\title{
Research Reservations: Response and Responsibility in an American Indian Community*
}

\author{
Joseph P. Gone
}

Published online: 23 June 2006

(C) Springer Science+Business Media, Inc. 2006

\begin{abstract}
Community action research among the Assiniboine and Gros Ventre tribes of the Fort Belknap Indian reservation in Montana was undertaken to identify the cultural grounds for innovative mental health service delivery. As an enrolled tribal member investigating these matters in my "home" community, however, I encountered a series of challenges and limitations emerging from respondent reservations about sharing personal experiences of difficulty and distress, and the perceived means for redressing these. Focusing upon a difficult interview with a knowledgeable tribal elder, I enlist sociolinguistic analysis-the study of communicative norms governing who talks with whom about what (and under which conditions) — as one crucial means to making sense of this complex research encounter. Similar analyses would seem necessary to ensuring the cultural validity of research conclusions in cross-cultural action research more generally.
\end{abstract}

Keywords American Indians · Mental health · Community psychology $\cdot$ Cultural diversity $\cdot$ Sociolinguistics $\cdot$ Action research

\footnotetext{
* An enrolled member of the Fort Belknap Indian Community of Montana, Joseph P. Gone is currently an assistant professor in the Department of Psychology (Clinical Area) and the Program in American Culture (Native American Studies) at the University of Michigan.
}

\section{J. P. Gone $(\bowtie)$}

Department of Psychology, University of Michigan,

530 Church Street, Ann Arbor, MI 48109-1043, USA

e-mail: jgone@umich.edu

\section{Introduction}

In the summer of $1999,{ }^{1}$ I ventured home to the Fort Belknap Indian reservation in north-central Montana to undertake an exploratory ethnographic investigation of the complicated relationships between culture, drinking, and depression among the Assiniboine and Gros Ventre peoples who reside there. During one particularly memorable interview with a $\mathrm{Na}$ tive American traditionalist and outspoken cultural advocate (Gone, 2006d, 2006e), I inquired as to the circumstances under which he might consider referring a loved one to the mental health program at the local Indian Health Service clinic. With soft words, underscoring the sobriety of his convictions on the matter, this thoughtful middle-aged tribal member replied:

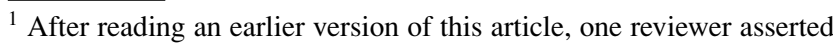
that: "Ordinarily ethnographers and researchers who conduct fieldwork with indigenous communities do not mention the name of the reserve or tribe(s). In fact, ethical guidelines are discouraging use of community names to protect the anonymity and integrity of the group." Not surprisingly, this reviewer recommended that the name of my community and any related geographic identifiers be removed from the manuscript. A series of congenial negotiations with the editors on this subject ensued, in which I explained that the reviewer's assertion was in fact not characteristic of much research in tribal communities, particularly in research that was intimately concerned with the distinctive cultural practices of a specific people-indeed, my own Institutional Review Board approved this research absent any ethical concerns on this point. More importantly, however, I argued that explicitly identifying my own reservation community in this essay was both my right and responsibility as a tribal citizen and community member. Although a nuanced discussion of these issues must await future publication, I will simply observe here that blanket assertions that "specific [tribal] communities should not be identified in professional publications" (Norton \&
} 
That's kind of like taboo. You know, we don't do that. We never did do that. If you look at the big picture-you look at your past, your history, where you come from-and you look at your future where the Whiteman's leading you, I guess you could make a choice: Where do I want to end up? And I guess a lot of people want to end up looking good to the Whiteman. Then it'd be a good thing to do: Go [to the] white psychiatrists in the Indian Health Service and say, "Rid me of my history, my past, and brainwash me forever so I can be like a Whiteman." I guess that'd be a choice each individual will have to make.

Now because mental health professionals typically invest time and energy in completing their training and establishing their credentials out of humanitarian intent and concern, the contention of this seasoned cultural advocate that even well-intended clinical efforts may in fact extend and sustain the historic American project of "civilizing" its savage frontier seems rather disquieting. And yet, given the cultural origins of most conventional clinical practices (grounded as they are in the fundamental "western" traditions of individualism, dualism, and secular modernity), is it really so difficult to imagine that even the most "culturally competent" of clinicians might, in many quite crucial respects, engage routinely (if inadvertently) in the prescription of western selves (or "subjectivities") to the distressed Native American "patient" or "client"? That is, regardless of their individual political sentiments and sensitivities as conscientious and compassionate people, is it not possible that the professional roles and tools of the trade into which mental health workers have been enculturated are saturated with-even constituted by - the norms, notions, privileges, assumptions, and expectations of the U.S. dominant culture (Gone, 2003, 2004a, 2004b, 2006a, 2006c, 2006d, 2006e)? In sum, could it be that this Native American traditionalist is right: that conventional mental health services in Indian country (and, by extension, in other communities of color as well) involve a subtle but significant form of cultural "brainwashing"?

Community psychology, of course, is no stranger to critiques of conventional mental health service delivery on several grounds, including cultural ones (for an early discussion, see Rappaport, 1977). Since conventional mental heath resources remain culturally incongruent with the traditions and practices of most American Indian reservation communities, new forms of programmatic intervention are necessary to ensure that such community-based efforts are fully accessible, culturally appropriate, and demonstrably effective (Gone \& Alcántara, in press). The result of my preliminary investigation, then, was a commitment to a collaborative, sustained, and empowering relationship with tribal members on the

Manson, 1996, p. 859) have not been properly contextualized or interrogated for community researchers to have foreclosed on the subject.
Fort Belknap reservation whereby innovative interventions designed to facilitate psychological resilience and prevent dysfunction within the community could be developed, refined, and scientifically assessed in a culturally consonant manner. It quickly became evident, however, that progress toward the development of appropriately innovative interventions would first require a systematic account of the cultural construal of self, personhood, affect, disorder, wellness, healing, spirituality and social relations within the reservation setting in order to ensure the ultimate cultural validity of any novel programmatic efforts (Gone, 2003, 2004a, 2004b, 2006e).

So it was that I commenced ethnographic "fieldwork" among my own people at Fort Belknap during the summer of 2001 in order to ascertain more clearly the cultural parameters of wellness, distress, and healing (broadly conceived). Through careful observation and open-ended interviews with a range of knowledgeable respondents, I sought to identify the nuances of local experience and expression as a foundation of knowledge for the future design, implementation, and assessment of any innovative "mental health" programs for the Fort Belknap community. The unique opportunity (and simultaneous challenge) for me was that I am both tribal member (albeit one unfamiliar with reservation life until my early adulthood) and community action researcher (albeit one dedicated to making my work relevant to this particular community). I thus anticipated that through this unprecedented intersection of roles and identities I might discover (where other researchers would or could not) an effective means to study and understand in nuanced cultural terms the local contours of "mental health" within my home community. In sum, I sought to negotiate the dilemma of insider-outsider status for the purposes of establishing a viable program of community action research.

\section{The Research Context: A Contemporary Overview of the Fort Belknap Indian Reservation}

Homeland to the Assiniboine and Gros Ventre peoples of the northern Plains, the Fort Belknap Indian reservation was established in north-central Montana in 1889. Comprised of more than one million acres held in federal trust, the reservation proper distances some forty miles north to south and twenty-six miles east to west, with the Milk River and the Little Rocky Mountains delineating the northern and southern boundaries respectively. Between the river and the mountains stretches a sea of rolling prairie, with an occasional butte or creek intruding upon the omnipresent grasslands. Four small communities dot the reservation landscape, including Fort Belknap Agency in the northwestern quadrant where the tribal headquarters and government agencies are situated. Tribal government on the reservation is regulated by 
the Constitution of the Fort Belknap Indian Community. Following the most recent amendments to the tribal constitution, the Fort Belknap Community Council now consists of five Assiniboine and five Gros Ventre councilpersons, including a president and vice-president team, chosen by enrolled members of voting age. These elected officials are responsible for all of the administrative, legislative and financial affairs of the reservation, maintaining the government-to-government relationship with the United States. The Council oversees some two hundred employees in roughly 50 federally-funded but tribally-controlled programs managed for the benefit of tribal citizens. In addition, the Council routinely advocates and negotiates with officials from the Bureau of Indian Affairs and the Indian Health Service on behalf of tribal interests-it is this latter agency that is explicitly tasked with providing "behavioral health" services to community members.

The two tribes at Fort Belknap keep separate membership records, with the Assiniboines numbering under 2500 members and the Gros Ventres numbering over 3000 members. Membership (or citizenship) in one of the two tribes is signified by "enrollment" based upon degree of tribal ancestry. Enrollment currently requires that an individual prove at least one-eighth or more Assiniboine and/or Gros Ventre "blood," and forego membership in any other tribal nation. Enrollment affords the member the benefits and privileges of citizenship in the "domestic dependent nation" known as the Fort Belknap Indian Community: health care, educational resources, favored employment status, voting rights, etc. (for more information regarding the rights of Indians and tribes, see Pevar, 2002). Although the two tribal groups have intermarried to a large extent over the years, both with each other and with outsiders, separate tribal identities persist. Thus, even though both tribes are heirs to the prototypical nomadic horse culture of the high Plains, there remain marked differences in cultural expression between the two tribes. Points of contention include tribal accounts of who came first to the area now encompassed by Fort Belknap as well as tribal beliefs about superiority in handling reservation political and economic affairs (see Fowler, 1987, for a thorough ethnohistory of Fort Belknap).

Since it is commonplace for individuals and families at Fort Belknap to circulate to towns and cities throughout the region in search of housing, employment, or education, only half of all tribal members reside on or near the reservation at any given time. The fact that so many tribal members live away from the reservation (returning as fortunes change, family responsibilities dictate, or retirement allows) is a consequence of the chronically depressed reservation economy. Throughout the reservation era, the residents of Fort Belknap have depended primarily upon the rather unpredictable pursuits of agriculture and livestock for their livelihood. As a result, unemployment is high at Fort Belknap, with local estimates suggesting that eighty percent of the resident pop- ulation is out of work during the winter season. The primary sources of stable income today are employment with the federally funded programs sponsored by Congress in fulfillment of its Trust Responsibility to the tribal nations. Thus, the Bureau of Indian Affairs, Indian Health Service, and Community Council together employ several hundred people. In recent years, the Council has sponsored a handful of business ventures, such as a tribally-owned convenience store and cafe as well as an industrial plant that produced landmine parts for the U.S. Army. In addition, a tribally controlled community college has been growing steadily since the early 1980s, offering hundreds of residents renewed ambitions and upward mobility. Still, the most recent U.S. Census figures indicate that 36.5 percent of families at Fort Belknap were living below the poverty level. Not surprisingly, residents of Fort Belknap are more susceptible to the usual social correlates of poverty: a slightly lower life expectancy with higher rates of substance abuse, violence, crime, health and mental health problems, and demoralization.

During my summer research visit in 2001, I sought to understand the cultural, social, and historical contexts for these problems and their perceived solutions, especially as they pertained to contemporary mental health service delivery. The specific objectives of my investigation included: (1) examination of the culturally constructed experience and expression of "distress" among American Indian respondents at Fort Belknap; (2) description of local "healing" resources deemed effective for facilitating adaptive coping among distressed members of the reservation communities; (3) identification of especially salient forms of distress that seemed to warrant the development of innovative interventions; and (4) coordination of local authorities and institutions in preparation for the submission of a competitive NIH grant application to move forward with the design of an innovative intervention targeting salient forms of distress in the near future. The methods I sought to employ were primarily ethnographic and involved loosely structured interviews with a range of knowledgeable respondents, including local policy makers, spiritual leaders, health service providers, human services educators, and individuals otherwise identified for their first-hand experiences in regard to the management of psychological distress. In addition to formal interviews, ongoing participant-observation in pertinent settings was expected to provide the contextual backdrop for interpreting interview data. Unfortunately, as the summer weeks drifted by, realization of these objectives seemed increasingly remote.

\section{The Research Challenge: Identifying Responsive Respondents}

The irony of conducting mental health research in Indian country is that most American Indian people I have en- 
countered do not typically desire to discuss their "mental health" with others, especially strangers. This is true at Fort Belknap as well, where tribal members have historically relied upon ferocity, tenacity, and uncommon "strength of mind" to negotiate their nomadic life on the far northern Plains and later to contend with Euro-American colonialism. The result is a subtle but influential cultural patterning of distress that governs who talks with whom about which kinds of troubling experiences (and under what conditions). These communicative norms that structure local experience and expression of distress lead to emotional reserve and forbearance in the vast majority of interpersonal circumstances, and certainly have not included unvarnished expressions of distress to mental health researchers (see Gone, 2004a, 2006b, 2006d, 2006e, in press, for more detailed contrast of the philosophy and practices constituting local healing tradition and professional psychology respectively). In essence, then, the principal challenge confronting this project was to identify an existing (or perhaps to create an innovative) interpersonal or relational context in which communication about the experience and expression of distress by tribal members for the purposes of community action research was possible. I hoped that my position as a recognized member of a large extended family on the reservation might facilitate success in this regard.

One of my first interviews that summer proved emblematic of the many kinds of difficulties I was later to encounter. At the outset, I was simply eager to commence my inquiry with knowledgeable tribal elders who were highly regarded in the community for their cultural authority and expertise. For several reasons, one particular elder came immediately to mind. For one thing, Marvin (a pseudonym) was exemplary of his particular generational cohort in rejecting Catholicism and embracing indigenous ceremonial and traditional practices as an alternative way of life (see Fowler, 1987, for delineation of generational cohorts at Fort Belknap). His credentials in this regard were exceptional by Fort Belknap standards: he had (as he later informed me) inherited the right and responsibility for conducting several traditional ceremonies and had participated avidly in various pan-Indian rituals for many years. Second, Marvin had brought his unique cultural expertise to bear in the support and treatment of Native American clients in a variety of human service settings throughout the region. Thus, his extensive experience in therapeutic settings with distressed American Indians promised unusual insight into the cultural dynamics of mental health service delivery at Fort Belknap. Finally, as an esteemed elder in the community, there was ample precedent in tribal tradition for a younger man such as myself seeking out an elderly community member for authoritative consultation on pressing cultural matters. In fact, similar consultations with another tribal elder concerning contemporary reservation cultural identity many summers ago yielded a host of astonishing insights, both academic and personal (see Gone, 1996, 1999; Gone, Miller, \& Rappaport, 1999). I therefore hoped that similar interactions with Marvin might simultaneously illuminate complex conceptual difficulties regarding culture and mental health.

For centuries, the traditional protocol observed by young men seeking counsel from their elderly "grandfathers" (who were not necessarily blood relatives) required a gift of tobacco. Historically, this gift of tobacco was offered in the form of a loaded pipe. Presentation of a pipe to an elderly man by a junior signaled that a significant favor or request was forthcoming. In response to such presentations, older men would typically invite the supplicant to speak his mind and then wait patiently for the junior to make his request plain. After full consideration of the request and careful evaluation of the supplicant's motivation and commitment, the elder would usually indicate his consent to the request by lighting the pipe and consuming the tobacco before returning the stem and bowl to the junior. Of course, an elder might decide not to honor the supplicant's request, in which case he would refuse to accept the pipe offering-refusal by an elder to grant any legitimate request, however, was considered bad form and risked both social sanction and supernatural consequence (see Cooper, 1957, for much more detail). In order to petition Marvin's participation in my research "in a good way" (i.e., in a respectful and deferential observation of protocol), I decided to adhere to the modern instantiation of this custom by bringing a carton of cigarettes with me as I parked near his home in the breezy twilight of the reservation's vast horizon.

Marvin was talking on the telephone when I appeared on his doorstep. He waved me inside, finished his phone conversation, greeted me warmly, and invited me to sit. I placed the cigarettes on the edge of his kitchen table and pulled up a chair as he retrieved a cool beverage for me. He explained that he had been conversing with his grandchild on the phone, and expressed the anxieties and concerns that only a grandparent can harbor about the many challenges confronting young people who come of age on the reservation. Taking a seat across the table from me, he eventually observed that I had brought tobacco and asked what he could do for me. I offered a description of my project by explaining that I had obtained a small grant to interview people at Fort Belknap regarding culturally grounded alternatives to the extant behavioral health services on the reservation. I clarified that it seemed like the available services were not especially beneficial for many people who were going through difficult times. I added that I hoped such interviews could enable us to imagine an alternative form of helping system so that I could write a grant to try and fund such a system. I concluded by noting that since I was especially interested in cultural alternatives, there was really no one better to talk to than him. 
Marvin attended seriously to my words, and replied that he had one very important question about my project: for whom was I trying to develop this alternative system? I replied that I wanted to imagine something that would be useful to the community. He asked which community I meant. I indicated that I meant Fort Belknap generally, but didn't really know enough to be more specific than that. He clarified that a culturally oriented system would only be appropriate for culturally oriented people at Fort Belknap, but that many people on the reservation were not in fact "culturally oriented." The interview progressed rapidly from there. During the ensuing hours of my visit, Marvin regaled me with a lifetime's reflections on culture, colonialism, identity, "holistic wellness," and many other related matters. A central theme of his presentation-for I spoke only when directly and explicitly queried-emphasized the lengthy period of cultural development in pre-Columbian America that had culminated in ways of life that were perfectly tailored to supporting and sustaining harmony among all things, including the intrapersonal maintenance of holistic balance in the spiritual, physical, mental, and emotional realms. Since the Columbian invasion, Marvin explained, Native Americans have suffered dramatic cultural decline, leaving us with just a tiny fraction of our cultural practices to weather the extended range of stressors that our people now confront. He soberly observed that since it took seven generations to nearly destroy our cultural "coping mechanisms," it would probably take at least seven generations for the culture to flourish once again. This was due in part to the intergenerational transmission of dysfunction. He asked me pointedly how we might account for the intergenerational nature of this dysfunction among Native Americans. He observed that when I learned the answer to this question, I would be ready to write my grant.

I learned many other things of no small significance that evening, including that Native Americans currently need western psychiatry because our traditional resources are not presently adequate to preserve holistic wellness; that traditional language fluency was not necessary for the cultural revival that will ultimately restore the community to holistic wellness; that "Native Americans walk around with unresolved grief all their lives," but that our ceremonial practices - all of which involve healing-enable us to suppress this grief so that we can go about our daily affairs; and that our people are characteristically mean and ornery as a result of our fierce temperament, but that intermittent loss of our loved ones is the Great Mystery's way of offsetting this disposition by keeping our people humble through grief. In the context of such rich instruction, then, why have I already portrayed the interview as emblematic of several difficulties in conducting my research? In sum, even though Marvin shared many compelling insights with me that evening, he seemed somewhat affronted by the research process itself, undoubtedly leading to a reluctance to engage my project more fully.

For example, he was the only Indian respondent I have ever interviewed who tacitly indicated that the exchange was not to be audio-recorded (despite my rather modest effort to persuade him of the value of my preserving his exact words for my own private but accurate future instruction). In addition, his attitude on the matter was conveyed with such austerity that I dared not risk disrespect by taking notes during the interview-my record of our discussion was prepared from memory the following morning. Shortly after introducing the study as described above, Marvin retrieved a binder from his briefcase in the living room and placed it on the table in front of me, explaining that it was a curriculum he had developed for more culturally consonant human services. After he invited me to peruse its contents, I retrieved a copy of my respondent consent form for him to examine, and began to leaf through the curricular materials.

After some minutes passed, Marvin began reading portions of the consent form out loud, starting with the requisite paragraph detailing potential risks. As he encountered the sentence about using "the available resources for counseling or treatment at the Indian Health Service clinic or hospital" in case of interview-related distress, he grumbled that IHS would be the last place he would go for such assistance (see also Gone, 2006d, 2006e). He continued reading the consent form aloud through the sections covering compensation (\$10 per hour) and confidentiality. When he had concluded, I explained that the convoluted wording of the consent form was related to the legal issues that arise in protecting the rights of research respondents as the university monitors the activities of faculty members who venture forth to collect information for research purposes. By then, I was considering myself fortunate to have negotiated with my university's Institutional Review Board to allow verbal instead of written consent for the study-I doubt that Marvin would have been amenable to signing papers attesting to his consent to be interviewed. Nevertheless, in response to my offer to clarify any additional aspects of the consent process, Marvin raised no additional questions and instead proceeded with the interview by elaborating upon the curricular materials he had just shared. It was also significant that despite the centrality of these materials to the interview, Marvin never suggested that I should copy or obtain a copy of the materials-in fact, following my review of the binder he carefully retrieved it for safe keeping.

Much later in the interview, during a protracted discussion of Native identity and its relationship to wellness, Marvin fixed me with a formidable gaze and inquired sharply, "How does it feel to be an Apple Indian?" My eyes never left his during the pregnant pause that followed as the impact of his question settled around us. After a few moments, 
he resumed his presentation as if the question had floated away on the evening breeze. Finally, near the end of the interview, as an almost trivial aside, Marvin returned to the issue of respondent compensation. He noted that my offering him $\$ 10$ per hour for his contribution paled in comparison to the consultant fees he often commanded for his expertise. He observed that in just a few hours he had contributed more significant information than forty other respondents could have provided (and, in hindsight, he may have been relatively accurate in this assessment). He tapped the consent form and remarked, "This is exploitative." A short time later I departed, leaving two $\$ 20$ bills neatly tucked into the flap of the cigarette carton still sitting on Marvin's kitchen table.

I have asserted that my interview with Marvin was emblematic of future difficulties in conducting my research that summer. For even though several people in the community later shared their insights and experiences with me, relatively few were interested or willing to participate in formal research interviews, especially when the focus concerned their own difficulties and struggles. Not surprisingly, then, most of my remaining interviews were conducted with service providers or, occasionally, members of my own extended family (and, in some instances, my respondents occupied both statuses). In the end, once my research trip was abruptly curtailed by the events of September 11, the objectives of my endeavor to introduce community action research into my own tribal community remained largely unfulfilled.

\section{Reflections and Discussion: The Sociolinguistic Imperative}

I have already framed the chief lessons to be drawn from the foregoing presentation as principally concerned with $\mathrm{cul}$ tural patterns of communication. The field explicitly devoted to the study of such patterns is known as the ethnography of speaking or sociolinguistics. Sociolinguistic analysis is concerned with the social organization of speech practices that entails both a shared form of speech (i.e., the language proper) as well as practical knowledge of its patterns of use (i.e., the meta-communicative norms that regulate speech acts). Thus, according to Hymes (1974), the sociolinguistic enterprise must render an ethnographic account of who speaks with whom about what (and under which circumstances) for a given speech community. The sociolinguist Charles Briggs (1986) has explored the implications of the ethnography of speaking for the cross-cultural research interview. More specifically, Briggs has written of the many "communicative blunders" he made during his attempts to understand the lives and activities of Spanish-speaking Mexicanos in Cordova, New Mexico. He argues that such "blunders" or breakdowns in communication afford the cross-cultural researcher a unique opportunity to assess the often-divergent meta-communicative assumptions that interviewers and respondents invoke during research interviews. These assumptions might include, for example, relatively tacit understandings of the function or purpose of the interview (e.g., advancing science, representing the community, earning a quick buck, etc.) or the implicit equating of the interview situation with a more familiar kind of culturally salient discursive event (e.g., offering a sworn deposition, obtaining absolution from a priest, joshing an intrusive outsider, etc.).

As a result, Briggs notes that the interviewer "stands as a co-participant in the construction of a discourse" (p. 25) and that "contexts are the interpretive frames that are constructed by the participants in the course of the discourse" (p. 12). That is, given the potential for divergence in metacommunicative understanding between interviewer and respondent in cross-cultural research, such interviews must be seen to involve the dialogic negotiation of meaning between interlocutors that requires analytic attention in its own right if the validity of inferences based upon interview data is to be adequately established. The implication of this perspective for cross-cultural interviewing, then, is that the apparently "self-evident" meanings of the interview responses (i.e., "letting the data speak for themselves") must be examined in light of the meaning of the interview situation itself. Thus, a sociolinguistic approach asserts that the cross-cultural investigator must observe and discern through every step of the research how local norms of interaction, discursive practice, and communicative conduct are shaping the exchange of information so as to maximize the interpretability and cultural validity of participant responses. This is no small task, as each new research encounter necessitates negotiation and re-negotiation of interpersonal relationships within cultural context.

Clearly, the communicative norms at Fort Belknap both facilitated and constrained my research efforts in significant ways. The larger sociolinguistic challenge, of course, is to explicate with more analytic precision just what those norms were and how they impacted my research. In regard to my interview with Marvin, there were clear ambiguities regarding the most appropriate "interpretive frame" that might have contextualized our particular communicative encounter. In fact, such ambiguity characterized my own deliberate strategy to merge divergent genres of speech (e.g., the "ethnographic research interview" and the "supplication of tribal elders") in the effort to craft an insider-outsider identity that I hoped would facilitate my ability to effectively undertake action research in a community that is deeply suspicious of outsiders in general and researchers in particular. My experience of interviewing Marvin suggests, however, that the merging of speech genres from disparate cultural 
contexts-especially when further inflected by the interpretive frames brought to the encounter by respondents themselves-is no simple matter. For despite the many ambiguities that linger, the pricklier moments in my interview with Marvin remain most salient to me. As a result, I am still unsettled by our exchange, because tied up in it were so many of my long-nourished aspirations to "give psychology away" (Miller, 1969) to the people I care for most in the world. Now instead, like the commentator on my very first published journal article (see Crapanzano's (1999) commentary on Gone (1999)), I am sometimes tempted to recoil from the notion of "objectifying" my own people for the purposes of research.

The description of my interview with Marvin, of course, was meant to exemplify and elucidate the communicative, relational, and interpersonal dynamics of my research at Fort Belknap more generally. Obviously, in some cases involving other potential respondents, the communicative context was all wrong-I was not the right gender, the right age, or from the right family to talk with about certain kinds of psychological difficulty or distress. Furthermore, any claim I might lay to "insider" status is based largely upon kinship ties and more recent community involvement rather than cultural fluency purchased through long years of early socialization at Fort Belknap. In addition, certain key community members declined to participate in my research because of my previous activities in the community as a political appointee of a controversial Community Council. Finally, a few members of my extended family - who were extremely supportive of my research for motivations other than furthering the production of knowledge in community psychologywondered why I was so rarely available to spend time with them even though I was at home for an unusually lengthy stay.

And yet, Marvin did in fact "consent" to be interviewed and provided profound instruction to me-confirmed by triangulation with the testimony of other respondents-on many matters of pressing relevance for conceptualizing culture and mental health at Fort Belknap. Unfortunately, I do not possess the necessary understanding to authoritatively interpret our exchange: is it possible, for example, that my offering of tobacco obliged Marvin to share with me beyond his own comfortable inclination? Or, alternatively, is it possible that the more challenging moments of our interview were Marvin's way of testing my sincerity and resolve-in short, my tenacity (Gone, 1996, 2006b) — before deciding whether to entrust me with potentially transformative knowledge? In any case, the principal lesson I draw from this experience is that researchers intent upon undertaking action research in diverse contexts would do well to attend to the communicative (or "sociolinguistic") norms governing interpersonal interaction in order to account for their own positioning within the discursive field of the communities in which they work.
This seems an essential means to ensuring the cultural validity of their findings.

Furthermore, it is crucial to note that such understandings might imply research strategies that depart substantively from the institutionalized norms dictating, for example, how consent is obtained (e.g., signed contractual documentation versus trustworthy interpersonal relations) or compensation provided (e.g., payment for services rendered versus generous inauguration of a cycle of reciprocity). For this article in particular, I have grappled with conventional notions of confidentiality in community research, desiring both to represent and reflect my "home" community (and my place within it) with transparency, fidelity, and respect, while simultaneously protecting the anonymity of individuals who have taught me a great deal through the research process. In sum, the dilemmas I encountered at Fort Belknap-though exacerbated to an extreme degree by my unusual positioning within this community - may well extend in more limited fashion to research conducted in almost any Native American community, whether by insiders, outsiders, or hybrids like me. A final paradox, of course, is that a thorough specification of the relevant communicative norms insofar as they impacted my research at Fort Belknap during the summer of 2001 (and might well impact similar research in the future) would itself require subsequent research at Fort Belknap in which such norms might once again threaten to frustrate the very objectives of the investigation.

\section{References}

Briggs, C. L. (1986). Learning how to ask: A sociolinguistic appraisal of the role of the interview in social science research. Cambridge, England: Cambridge University Press.

Cooper, J. M. (1957). The Gros Ventres of Montana: Part II. Religion and ritual. Washington, DC: Catholic University of America.

Crapanzano, V. (1999). Directed reflections: Pragmatic and metapragmatic corralling. Ethos, 27(4), 536-549.

Fowler, L. (1987). Shared symbols, contested meanings: Gros Ventre culture and history, 1778-1984. Ithaca, NY: Cornell University.

Gone, J. P. (1996). Gros Ventre cultural identity as normative self: A case study. Unpublished master's thesis, University of Illinois, Champaign.

Gone, J. P. (1999). We were through as Keepers of it: The "Missing Pipe Narrative" and Gros Ventre cultural identity. Ethos, 27(4), $415-440$.

Gone, J. P. (2003). American Indian mental health service delivery: Persistent challenges and future prospects. In J. S. Mio \& G. Y. Iwamasa (Eds.), Culturally diverse mental health: The challenges of research and resistance (pp. 211-229). New York: BrunnerRoutledge.

Gone, J. P. (2004a). Keeping culture in mind: Transforming academic training in professional psychology for Indian country. In D. Mihesuah \& A. Cavender-Wilson (Eds.), Indigenizing the academy: Transforming scholarship and empowering communities (pp. 124-142). Lincoln, NE: University of Nebraska Press. 
Gone, J. P. (2004b). Mental health services for Native Americans in the 21st century United States. Professional Psychology: Research and Practice, 35(1), 10-18.

Gone, J. P. (2006a). Encountering professional psychology: Reenvisioning mental health services for Native North America. Manuscript submitted for publication.

Gone, J. P. (2006b). "I came to tell you of my life" : Narrative expositions of "mental health" in an American Indian community. Manuscript submitted for publication.

Gone, J. P. (2006c). Mental health, wellness, and the quest for an authentic American Indian identity. In T. Witko (Ed.), Mental health care for urban Indians: Clinical insights from Native practitioners (pp. 55-80). Washington, DC: American Psychological Association.

Gone, J. P. (2006d). "So I can be like a Whiteman": The ethnopsychology of space and place in American Indian mental health service delivery. Manuscript submitted for publication.

Gone, J. P. (2006e). "We never was happy living like a Whiteman": Mental health disparities and the postcolonial predicament in American Indian communities. Manuscript submitted for publication.

Gone, J. P. (in press). "As if reviewing his life": Bull Lodge's narrative and the mediation of self-representation. American Indian Culture and Research Journal.
Gone, J. P., \& Alcàntara, C. (in press). Practice makes perfect?: Identifying effective psychological treatments for mental health problems in Indian country. In E. H. Hawkins \& R. D. Walker (Eds.), Best practices in behavioral health services for American Indians and Alaska Natives. Portland, OR: One Sky National Resources Center for American Indian and Alaska Native Substance Abuse Prevention and Treatment Services.

Gone, J. P., Miller, P. J., \& Rappaport, J. (1999). Conceptual self as normatively oriented: The suitability of past personal narrative for the study of cultural identity. Culture \& Psychology, 5(4), 371398.

Hymes, D. (1974). Foundations in sociolinguistics: An ethnographic approach. Philadelphia: University of Pennsylvania Press.

Miller, G. A. (1969). Psychology as a means of promoting human welfare. American Psychologist, 24, 1063-1075.

Norton, I. M., \& Manson, S. M. (1996). Research in American Indian and Alaska Native communities: Navigating the cultural universe of values and process. Journal of Consulting and Clinical Psychology, 64(5), 856-860.

Pevar, S. L. (2002). The rights of Indians and tribes: The authoritative ACLU guide to Indian and tribal rights (3rd ed.). Carbondale, IL: Southern Illinois University Press.

Rappaport, J. (1977). Community psychology: Values, research, and action. Fort Worth, TX: Holt, Rinehart, and Winston. 